\title{
Midlatitude Wind Stress-Sea Surface Temperature Coupling in the Vicinity of Oceanic Fronts
}

\author{
Michael A. Spall \\ Department of Physical Oceanography, Woods Hole Oceanographic Institution, Woods Hole, Massachusetts
}

(Manuscript received 11 September 2006, in final form 4 December 2006)

\begin{abstract}
The influences of strong gradients in sea surface temperature on near-surface cross-front winds are explored in a series of idealized numerical modeling experiments. The atmospheric model is the Naval Research Laboratory Coupled Ocean-Atmosphere Mesoscale Prediction System (COAMPS) model, which is fully coupled to the Regional Ocean Modeling System (ROMS) ocean model. A series of idealized, two-dimensional model calculations is carried out in which the wind blows from the warm-to-cold side or the cold-to-warm side of an initially prescribed ocean front. The evolution of the near-surface winds, boundary layer, and thermal structure is described, and the balances in the momentum equation are diagnosed. The changes in surface winds across the front are consistent with previous models and observations, showing a strong positive correlation with the sea surface temperature and boundary layer thickness. The coupling arises mainly as a result of changes in the flux Richardson number across the front, and the strength of the coupling coefficient grows quadratically with the strength of the cross-front geostrophic wind. The acceleration of the winds over warm water results primarily from the rapid change in turbulent mixing and the resulting unbalanced Coriolis force in the vicinity of the front. Much of the loss/gain of momentum perpendicular to the front in the upper and lower boundary layer results from acceleration/ deceleration of the flow parallel to the front via the Coriolis term. This mechanism is different from the previously suggested processes of downward mixing of momentum and adjustment to the horizontal pressure gradient, and is active for flows off the equator with sufficiently strong winds. Although the main focus of this work is on the midlatitude, strong wind regime, calculations at low latitudes and with weak winds show that the pressure gradient and turbulent mixing terms dominate the cross-front momentum budget, consistent with previous work.
\end{abstract}

\section{Introduction}

There is now a large body of evidence that the nearsurface winds in the atmosphere are modified in the vicinity of oceanic fronts. Early studies in the eastern tropical Pacific Ocean found a strong correlation between surface wind and sea surface temperature such that winds were stronger over warmer water (Wallace et al. 1989). In situ observations have revealed a similar relationship at midlatitudes near the Gulf Stream (Sweet et al. 1981; Mahrt et al. 2004), western Arabian Sea (Vecchi et al. 2004), Agulhas Current (Jury and Walker 1988), and Kuroshio (Nonaka and Xie 2003). High-resolution satellite observations have demonstrated that this correlation between sea surface tem-

\footnotetext{
Corresponding author address: Michael A. Spall, Department of Physical Oceanography, Woods Hole Oceanographic Institute, MS \#21, 360 Woods Hole Road, Woods Hole, MA 02543.

E-mail: mspall@whoi.edu
}

perature and surface wind stress is found on spatial scales of $25-1000 \mathrm{~km}$ and extends to seasonal and interannual time scales (Chelton et al. 2001, 2004; O'Neill et al. 2003, 2005; Xie 2004; Xie et al. 2001).

Several hypotheses have been put forth to explain the correlation between SST and surface winds, and a recent review of observational and modeling results is given in Small et al. (2007, manuscript submitted to Dyn. Atmos. Oceans). Lindzen and Nigam (1987) suggested that the change in surface winds in the tropical Pacific Ocean result from an adjustment to pressure gradients that are set up across ocean fronts due to the different baroclinic structure of the boundary layer on either side of a front. The importance of pressure gradients in the generation of strong winds over warm water has been inferred from models of the eastern equatorial Pacific (Small et al. 2003, 2005) and observations and models over the Gulf Stream (Mahrt et al. 2004; Song et al. 2006).

Wallace et al. (1989) and Hayes et al. (1989) pro-

DOI: $10.1175 /$ JCLI4234.1 
posed that the decrease in stability of the boundary layer over warm water results in an increase in the turbulent mixing in the planetary boundary layer, and thus enhances the downward mixing of momentum from the upper atmosphere to the near surface. This enhanced downward turbulent mixing results in stronger surface winds over warm water. Support for the vertical mixing of momentum idea is found in the near-equatorial model of de Szoeke and Bretherton (2004) and the midlatitude large eddy simulations of Skyllingstad et al. (2006).

Samelson et al. (2006) suggest that the stress at the sea surface must depend on the planetary boundary layer thickness so that the surface winds must be positively correlated with boundary layer thickness and, thus, sea surface temperature. Their analysis did not consider the transitional region near the ocean front where winds are accelerating and applies only to the near-equilibrium regions away from the front.

\section{Model configuration and examples}

\section{a. Model configuration}

A series of idealized, two-dimensional coupled ocean-atmosphere numerical model calculations have been carried out in order to explore the nature of the coupling between sea surface temperature and the overlying atmospheric winds. The atmospheric component is the three-dimensional Naval Research Laboratory Coupled Ocean-Atmosphere Mesoscale Prediction System (COAMPS) model (Hodur 1997). The model solves the nonhydrostatic compressible equations of motion on a staggered terrain following sigma coordinate system in the vertical and a staggered C-grid in the horizontal. (Details can be found in the COAMPS User Guide available at http://www.nrlmry.navy.mil/ coamps-web/web/home.)

The model incorporates several surface and boundary layer parameterizations. The Mellor and Yamada (1982) level-2.5 turbulence closure scheme is used to parameterize turbulence on subgrid scales. This approach solves for the turbulent kinetic energy (TKE) $e$ using the TKE equation

$$
\begin{aligned}
\frac{\partial}{\partial t}(e)= & \frac{\partial}{\partial z}\left(K_{e} \frac{\partial}{\partial z}(e)\right)+K_{M}\left(\frac{\partial U}{\partial z}\right)^{2}+K_{M}\left(\frac{\partial V}{\partial z}\right)^{2} \\
& -\beta g K_{H} \frac{\partial \theta}{\partial z}-\frac{(2 e)^{3 / 2}}{\Lambda_{1}}+U \frac{\partial}{\partial x}(e)+V \frac{\partial}{\partial y}(e),
\end{aligned}
$$

where $D / D t=U \partial / \partial x+V \partial / \partial y+W \partial / \partial z$ is the material derivative; $e=\overline{\left(u^{2}+v^{2}+w^{2}\right) / 2}$ is the turbulent kinetic energy in which $u, v$, and $w$ are the unresolved turbulent velocities; $U$ and $V$ are the resolved horizontal velocity field; $\beta$ is the coefficient of thermal expansion; $\theta$ is potential temperature; and $g$ is the gravitational acceleration. This equation balances the material change of TKE with vertical diffusion, shear production, buoyancy production, dissipation, and lateral advection by the large-scale flow. The dissipation length scale $\Lambda_{1}$ is derived from a universal length scale $l$, defined below. The reader is referred to Mellor and Yamada (1982) and the COAMPS User Guide for details.

The mixing coefficients are calculated as

$$
K_{H, M, e}=S_{H, M, e} l(2 e)^{1 / 2},
$$

where $S_{H, M}$ are polynomial functions of the flux Richardson number and $S_{e}$ is taken to be constant. The mixing length scale $l$ is calculated following Blackadar (1962) as

$$
l=\frac{\kappa z}{1+\kappa z / \lambda} .
$$

Here $\kappa$ is the von Kármán constant and the parameter $\lambda$ is a turbulence weighted length scale given by

$$
\lambda=\alpha \frac{\int z e d z}{\int e d z},
$$

where the value of $\alpha$ depends on the stability of the atmosphere. For stable stratification, $\alpha=0.1$ and for unstable stratification $\alpha=0.1-z / 15 L$, for $-0.3<z / L<0$ and $\alpha=-0.3$ for $z / L<-0.3$, where $L$ is the MoninObukhov length.

The flux Richardson number is the ratio of the buoyant production of TKE to the shear production of TKE, given by

$$
\mathrm{Ri}_{f}=\frac{g / \theta_{V} \overline{\omega^{\prime} \theta_{V}^{\prime}}}{\overline{u^{\prime} \omega^{\prime}} U_{z}+\overline{v^{\prime} \omega^{\prime}} V_{z}} .
$$

The surface sensible heat flux, latent heat flux, and drag are calculated using the surface layer parameterization of Louis (1979), which makes use of the bulk Richardson number

$$
\mathrm{Ri}_{B}=\frac{g z_{10} \Delta \Theta}{u_{10}^{2} \Theta},
$$

where $z_{10}=10 \mathrm{~m}$ is a reference level, $\Delta \Theta$ is the air-sea temperature difference, $\Theta$ is the mean potential temperature over the depth of the surface layer, and $u_{10}$ is the wind speed at the reference level. 
The surface stress is related to the wind speed $\mathbf{U}$ and a drag coefficient $C_{D}$ as

$$
\tau=\rho_{0} \mathbf{U}^{2} C_{D}
$$

The drag coefficient is given by

$$
C_{D}=\left(\frac{\kappa}{\ln \left(z / z_{0}\right)-\psi(z / L)}\right)^{2},
$$

where $\psi$ is a stability-dependent correction function (Stull 1988).

A similar configuration of the COAMPS model was compared to a fully three-dimensional large eddy simulation model for flow directed from land over cold water by Skyllingstad et al. (2005). The COAMPS model tended to predict stronger mixing and a deeper boundary layer over cold water than was produced by the large eddy simulation model. The COAMPS model also produced very rapid transitions in turbulence levels between land and sea since the mixing length is controlled by the surface fluxes. However, the two models were found to produce qualitatively similar results in terms of the development of and momentum budgets within the boundary layer. With this in mind, the focus here is more on the general behavior of the boundary layer and influence of various terms on the momentum balances rather than a detailed prediction of how the boundary layer responds to variations in sea surface temperature.

The standard atmospheric model domain is $800 \mathrm{~km}$ in zonal extent and $9 \mathrm{~km}$ in the vertical. The horizontal resolution is $4 \mathrm{~km}$ and is uniform for all calculations reported here. Many of the calculations have also been carried out at $2-\mathrm{km}$ resolution and the results are essentially the same. The model is discretized with 47 sigma levels in the vertical with grid spacing varying from $1 \mathrm{~m}$ at the surface to $1000 \mathrm{~m}$ between $8-\mathrm{km}$ and 9-km height. There are 30 sigma levels in the lower 1 $\mathrm{km}$ of the atmosphere. A biharmonic diffusion is applied to control grid-scale noise. The latitude of the standard model domain is $43^{\circ} \mathrm{N}$, giving a Coriolis parameter of $10^{-4} \mathrm{~s}^{-1}$, taken to be constant. The boundary conditions in the meridional direction are periodic and a combination of radiation and extrapolation is used in the zonal direction.

The ocean model is the Regional Ocean Modeling System (ROMS; Shchepetkin and McWilliams 2005). ROMS solves the hydrostatic, Boussinesq primitive equations on a staggered $\mathrm{C}$-grid with a topographyfollowing sigma coordinate system in the vertical. The model uses horizontal Laplacian diffusion and viscosity parameterizations of subgrid-scale mixing (coefficients
$10 \mathrm{~m}^{2} \mathrm{~s}^{-1}$ ) and a background vertical diffusion and viscosity of strength $10^{-5} \mathrm{~m}^{2} \mathrm{~s}^{-1}$. The ocean model has a stretched grid in the vertical with 25 levels ranging from $7.7 \mathrm{~m}$ near the surface to $30 \mathrm{~m}$ near the bottom. The horizontal resolution is $4 \mathrm{~km}$, the same as for the atmosphere. The ocean domain is $D=500 \mathrm{~m}$ deep with a flat bottom. Lateral boundary conditions for the ocean are free slip on the eastern and western boundaries and periodic in the north-south direction. Boundary layers develop near the eastern and western walls in the ocean due to the Ekman transport away/toward the boundary forced by the atmospheric winds; however these boundaries are far from the region of the SST front and do not affect the solutions discussed here.

The atmosphere is initialized with an idealized potential temperature profile representative of that found at midlatitudes. For simplicity, the adiabatic lapse rate is constant at $6.7 \times 10^{-3}{ }^{\circ} \mathrm{C} \mathrm{m}{ }^{-1}$ and the surface temperature is $14^{\circ} \mathrm{C}$. The standard wind field is initialized as a zonal wind of strength $\pm 15 \mathrm{~m} \mathrm{~s}^{-1}$, although this will be varied. There is also a meridional pressure gradient imposed that balances this zonal wind so that it is initially in geostrophic balance. The initial meridional wind field is zero. The initial moisture profile varies linearly from $8 \mathrm{~g} \mathrm{~kg}^{-1}$ at the surface to $3 \mathrm{~g} \mathrm{~kg}^{-1}$ at the top of the atmosphere. The ocean is initialized with a uniform background stratification with the BruntVäisälä frequency $N^{2}=5 \times 10^{-5} \mathrm{~s}^{-2}$. A front is superimposed on this background stratification whose temperature change varies linearly in the vertical from $\Delta T$ at the surface to zero at the bottom. The initial temperature field in the ocean is defined by

$$
\begin{aligned}
T(x, z)= & T_{0}-N^{2} z / \alpha g \\
& +0.5 \Delta T\left\{1+\tanh \left[\left(x-x_{0}\right) / L f\right]\right\}(1-z / D),
\end{aligned}
$$

where $T_{0}$ is the sea surface temperature on the cold side of the front, nominally $15^{\circ} \mathrm{C}$, but will also be varied. The temperature change across the front is $\Delta T=5^{\circ} \mathrm{C}$. The ocean front is located in the center of the domain at $x_{0}=400 \mathrm{~km}$ and has a lateral decay scale of $L_{f}=30 \mathrm{~km}$.

The atmosphere and ocean models are fully coupled at the interface. The atmosphere obtains sea surface temperature from the ocean model, and the ocean model obtains the momentum flux, net longwave and net shortwave radiation and latent and sensible heat fluxes from the atmospheric model. The data are exchanged at the time step of the ocean model. Details of the coupling and solution procedure are given in Perlin et al. (2007).

Two classes of calculations will be considered: atmo- 

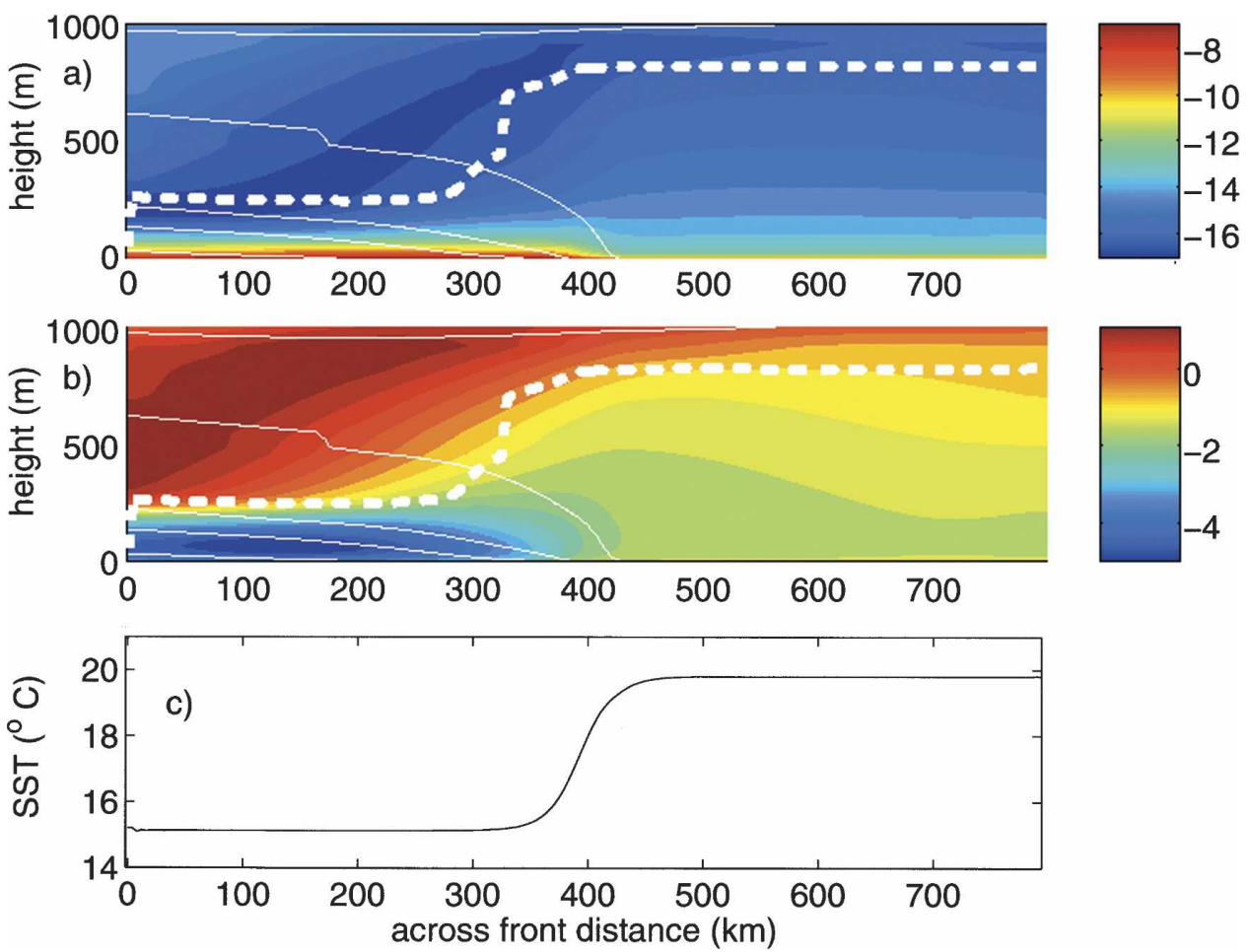

FIG. 1. Zonal sections of (a) zonal wind and (b) meridional wind (colors, units $\mathrm{m} \mathrm{s}^{-1}$ ) for the case of atmospheric flow from the warm side to the cold side of the front (right to left). Thin white contours are of potential temperature (contour interval: $1^{\circ} \mathrm{C}$ ) and the white dashed line is the top of the planetary boundary layer. (c) Sea surface temperature.

spheric flow from the warm side to the cold side of the ocean front and atmospheric flow from the cold side to the warm side of the front. Each of the model calculations are run for 48 hours by which time the fields are at an essentially steady state. Changes in SST are small over the course of integration and will not be discussed. Basic properties of the atmospheric circulation and boundary layers are first described in this section, and a discussion of the controlling physics and sensitivities are given in the following sections.

\section{b. Warm-to-cold example}

Results for the case with the atmospheric wind blowing from the warm side to the cold side of the front are given in Fig. 1. The entire domain is shown here, although subsequent figures will focus on the ocean frontal region and downwind evolution. The region between the inflow boundary on the right and the ocean front is nearly uniform with a boundary layer thickness of approximately $800 \mathrm{~m}$ (defined as the height at which the Richardson number exceeds 0.5 ) and zonal winds of $O\left(10-15 \mathrm{~m} \mathrm{~s}^{-1}\right)$. The temperature within the boundary layer is uniform, indicating strong turbulent mixing. The zonal winds at the top of the boundary layer are slightly supergeostrophic, while those near the surface are subgeostrophic. The meridional winds of $O\left(1 \mathrm{~m} \mathrm{~s}^{-1}\right)$ are to the south, or to the left of the geostrophic wind. This velocity profile and veering are consistent with the traditional linear Ekman layer flow, suggesting a balance between the Coriolis term and vertical turbulent mixing. Details of the momentum budget will be given in the next section.

As the flow crosses the front, the upper-level zonal winds accelerate and the near-surface zonal winds slow down. The boundary layer rapidly thins to approximately $250 \mathrm{~m}$. The temperature near the surface drops several degrees just downwind of the SST front. Such an internal boundary layer is commonly observed over cold water, as discussed by Mahrt et al. (2004), Skyllingstad et al. (2006), and Song et al. (2006). The meridional wind near the surface increases rapidly toward the south, which, together with the deceleration of the zonal flow, results in stronger veering of the wind. The meridional wind at heights between the shallow boundary layer over cold water $(250 \mathrm{~m})$ and the height of the boundary layer upwind over warm water $(800 \mathrm{~m})$ turns toward the north several hundred kilometers downwind of the SST front. 

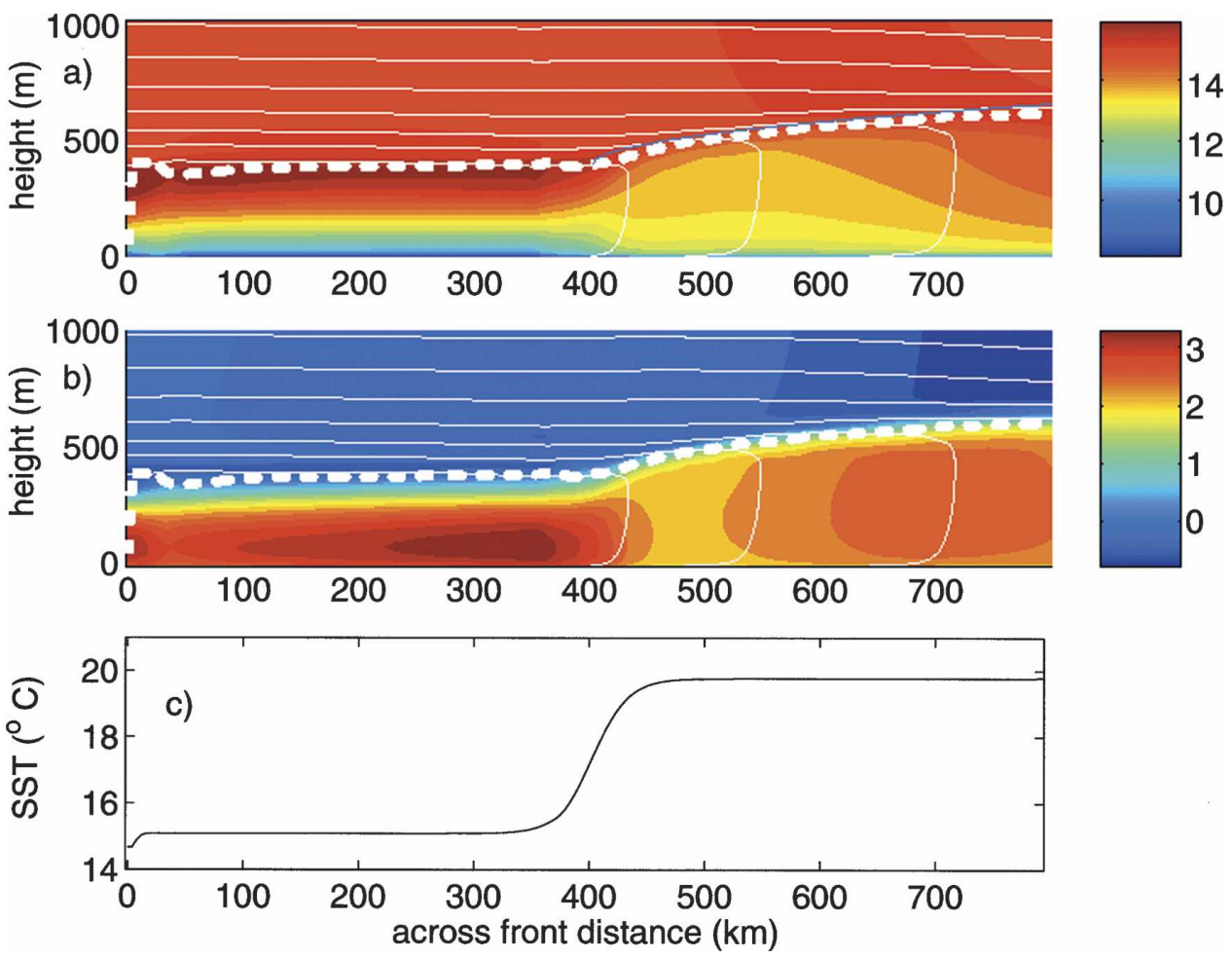

FIG. 2. Zonal sections of (a) zonal wind and (b) meridional wind (colors, units $\mathrm{m} \mathrm{s}^{-1}$ ) for the case of atmospheric flow from the cold side to the warm side of the front (left to right). Thin white contours are of potential temperature (contour interval: $1^{\circ} \mathrm{C}$ ), the white dashed line is the top of the planetary boundary layer, and the thin blue line in (a) is proportional to $x^{1 / 2}$ downwind of the front. (c) Sea surface temperature.

\section{c. Cold-to-warm example}

The calculation from cold to warm water shows a very different evolution (Fig. 2). Over the cold water, there is very strong vertical shear in the zonal winds with slightly supergeostrophic winds at the top of the boundary layer and with surface winds less than 10 $\mathrm{m} \mathrm{s}^{-1}$. The temperature is again nearly uniform with height within the 400-m-thick boundary layer. The meridional winds are to the north, again demonstrating veering relative to the zonal flow and consistent with an Ekman layer balance.

As the ocean front is crossed, the boundary layer gradually grows thicker, but over a much larger length scale than the collapse seen when going from warm to cold water. A similar asymmetry is discussed by Skyllingstad et al. (2006) and Song et al. (2006). The temperature in the boundary layer increases over a similar length scale and remains well mixed in the vertical over most of the boundary layer. There is a more rapid change in the zonal and meridional winds as the ocean front is encountered. The near-surface zonal wind increases by several meters per second while the meridional wind rapidly decreases. The upper-level zonal wind initially decreases as the boundary layer thickens, while the meridional winds increase. The upper-level zonal winds reach a minimum approximately $100 \mathrm{~km}$ downwind of the front and then gradually increase toward their geostrophic value. The meridional winds also increase on this same length scale.

In general terms, these model results are consistent with the observed changes in boundary layer thickness, wind speeds and directions, and levels of turbulence as in, for example, Mahrt et al. (2004), Smedman et al. (1997), Vickers and Mahrt (2006), Sweet et al. (1981), Vecchi et al. (2004), and Wallace et al. (1989). Similar changes across SST fronts have also been modeled by Small et al. (2003, 2005), Skyllingstad et al. (2006), and Song et al. (2006).

\section{Model analysis}

\section{a. Surface stress}

The surface winds change in response to the change in SST as the front is crossed. In both cases, the surface winds change on the same horizontal length scale as the change in SST. For the case of warm to cold, the zonal 

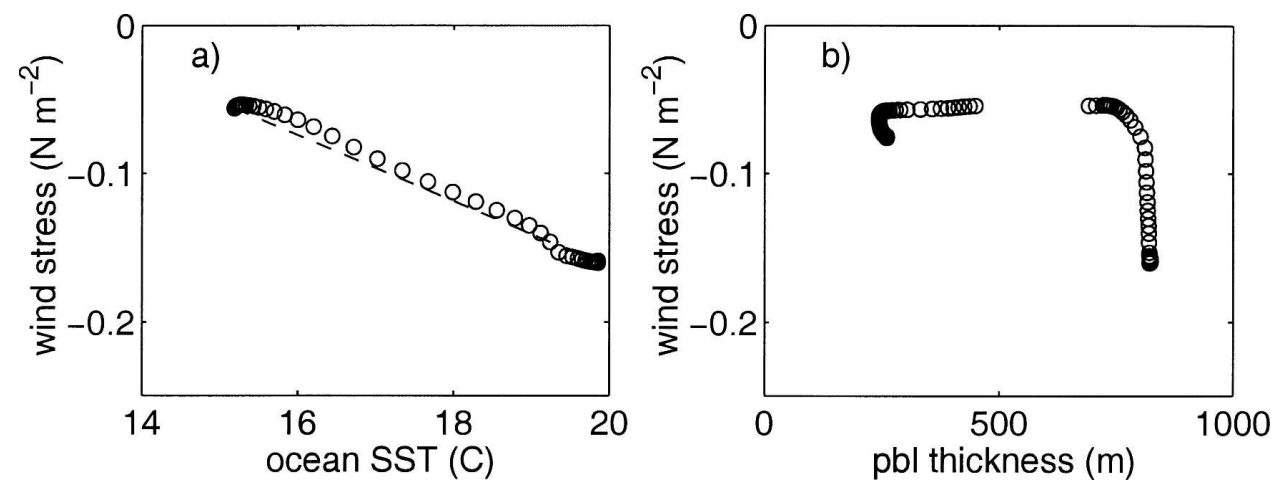

FIG. 3. Scatterplot of zonal surface wind stress versus (a) sea surface temperature and (b) planetary boundary layer thickness for the case of warm-to-cold flow. The dashed line in (a) is a linear trend with a slope of $-0.024 \mathrm{~N} \mathrm{~m}^{-2}{ }^{\circ} \mathrm{C}^{-1}$.

winds decrease from -11.5 to $-7.8 \mathrm{~m} \mathrm{~s}^{-1}$ over a distance of less than $100 \mathrm{~km}$. The corresponding surface stress decreases in magnitude from -0.16 to $-0.05 \mathrm{~N}$ $\mathrm{m}^{-2}$. This change in surface stress also takes place on the same scale as the change in SST.

There is a nearly linear relationship between SST and zonal surface stress, as indicated in Fig. 3a. The circles mark the zonal surface stress and SST at each model grid point. The farther apart the circles are spaced, the larger the horizonal gradient. Most of the change in zonal stress takes place where there is a large change in SST across the front. The slope of the dashed line, taken as the change in stress from 200 to $600 \mathrm{~km}$ in longitude, is $\alpha_{C}=\partial \tau / \partial T=-0.024 \mathrm{~N} \mathrm{~m}^{-2}{ }^{\circ} \mathrm{C}^{-1}$, which is in general agreement with the strength of the coupling found in satellite observations of O'Neill et al. (2003, 2005). However, there is not a clear relationship between the surface wind stress and the planetary boundary layer thickness in the vicinity of the front (Fig. 3b). Most of the change in surface stress takes place at nearly constant boundary layer thickness, while most of the change in boundary layer thickness is at nearly constant stress.

A similar result is found for the cold-to-warm calculation. The surface wind increases by approximately 3 $\mathrm{m} \mathrm{s}^{-1}$ over a distance of less than $100 \mathrm{~km}$, while the surface stress increases by $0.10 \mathrm{~N} \mathrm{~m}^{-2}$ (Fig. 4a). The surface stress is again nearly linearly related to the SST, this time with slope $\alpha_{C}=0.020 \mathrm{~N} \mathrm{~m}^{-2}{ }^{\circ} \mathrm{C}^{-1}$. As for the previous case, the changes in surface stress are found at nearly constant boundary layer thickness, while most of the change in boundary layer thickness occurs at nearly constant stress (Fig. 4b).

These results indicate that the simple, one-dimensional equilibrium balance proposed by Samelson et al. (2006), in which the surface stress is linearly related to the thickness of the boundary layer, does not hold in the vicinity of the front for either warm-to-cold or coldto-warm situations. This is not surprising since that balance was derived for quasi-equilibrium situations away from the rapid transitions that are expected to occur near the front. Away from the frontal region, the quali-
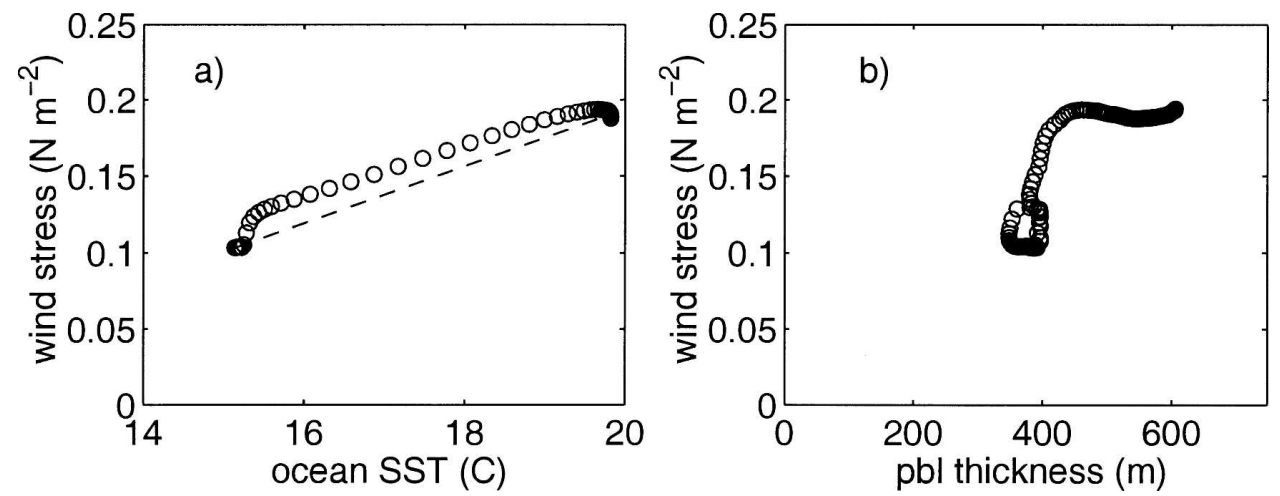

FIG. 4. As in Fig. 3 but for the case of cold-to-warm flow. The dashed line in (a) is a linear trend with slope $0.020 \mathrm{~N} \mathrm{~m}^{-2}{ }^{\circ} \mathrm{C}^{-1}$. 


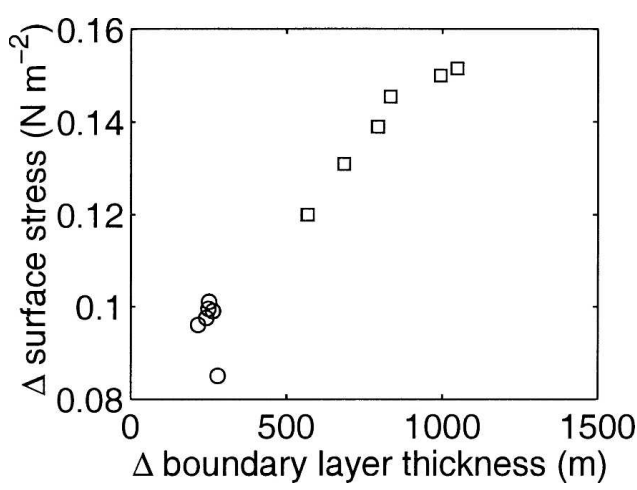

FIG. 5. Change in zonal surface stress versus change in planetary boundary layer thickness across the front for a series of model calculations in which the reference sea surface temperature $T_{0}$ is increased from $15^{\circ}$ to $20^{\circ} \mathrm{C}$. Circles indicate calculations from cold to warm; squares indicate calculations from warm to cold.

tative balance in the model is consistent with an Ekman layer that, in a linear constant mixing model, would produce a surface stress linearly proportional to the boundary layer thickness.

To test whether the one-dimensional balance of Samelson et al. (2006), and the linear relation predicted for a linear Ekman layer, hold away from the transitional region in the vicinity of the front, a series of calculations have been carried out in which the initial SST on the cold side of the front $\left(T_{0}\right)$ is increased from $15^{\circ}$ to $20^{\circ} \mathrm{C}$ in one-degree increments. Each of these oceanic states was run with winds from warm to cold and from cold to warm. These cases have the same $\Delta T$ across the front but result in deeper boundary layers in the atmosphere because of the warmer SST. The change in stress across the front for each of these calculations is plotted against the change in boundary layer thickness across the front in Fig. 5. The boundary layer thickness and stress on the downwind side of the front was calculated $200 \mathrm{~km}$ from the front, downwind of the region of rapid change in the surface stress. There is a generally linear trend of increasing change in surface stress across the front with the change in boundary layer thickness, consistent with the heuristic model of Samelson et al. (2006).

The warm-to-cold cases show the most sensitivity to changes in SST (squares), with the change in boundary layer thickness exceeding $1000 \mathrm{~m}$ for the warmest $T_{0}$. The cold-to-warm calculations show nearly the same change in thickness, and in surface stress, for all values of $T_{0}$. The upwind boundary layer thickness for the warm-to-cold calculations approaches the value it would have in an infinite domain with no spatial variation in SST, and this depends strongly on $T_{0}$. This is because the upwind boundary condition of radiation and extrapolation eliminates zonal gradients upwind of the front, so the balance there is essentially one-dimensional. However, for the cold-to-warm cases, the boundary layer is still growing in the downstream direction for all values of $T_{0}$ and so the change in boundary layer thickness is nearly independent of $T_{0}$ because the flow has not yet reached equilibrium.

The adjustment of the boundary layer thickness in the cold-to-warm cases is very close to what would be expected following a column of air subject to a destabilizing surface heat flux as it crosses the front. The boundary layer for a simple one-dimensional model subject to uniform heating at the surface would grow in time as $t^{1 / 2}$ (Turner 1973). Taking a Lagrangian view, with $x=t U$, and $x=0$ at the front, a boundary layer consistent with this one-dimensional model is shown in Fig. 2 by the solid blue line, which is close to what is found in the model.

Note also that the increasing change in stress across the front corresponds to an increasing slope in the relationship between surface stress and SST because each of these calculations has the same $\Delta T$. The slope of this relationship varies by almost a factor of 2 , ranging from $\alpha_{C}=1.7 \times 10^{-2}$ to $\alpha_{C}=3.0 \times 10^{-2} \mathrm{~N} \mathrm{~m}^{-2}{ }^{\circ} \mathrm{C}^{-1}$.

The subgrid-scale parameterization of vertical mixing of momentum was varied to determine the sensitivity of this coupling strength to the model formulation. The central case of cold-to-warm flow was recalculated for several cases: $K_{M}$ fixed to its value over warm water; $\psi=0.3$ and constant across the front; and $S_{M}=2$ and constant. All other formulations were as in the standard model. The first test case, with constant mixing across the front, resulted in very weak change in surface stress across the front, the coupling strength $\alpha_{C}=3 \times 10^{-3} \mathrm{~N}$ $\mathrm{m}^{-2}{ }^{\circ} \mathrm{C}^{-1}$, almost an order of magnitude smaller than the standard case. The mixing coefficient $K_{M}$ is a function of both mixing length $l$ and the polynomial function of the flux Richardson number $S_{M}$ [Eq. (2)]. Calculations with the mixing length fixed across the front produce essentially the same coupling strength as in the standard case. Calculations with the polynomial function fixed to a constant value $S_{M}=2$, which is close to that found over warm water for the standard calculation, produce only weak coupling of $\alpha_{C}=5 \times 10^{-3} \mathrm{~N}$ $\mathrm{m}^{-2}{ }^{\circ} \mathrm{C}^{-1}$. The sensitivity of the coupling strength to the change in $C_{D}$ as a result of the change in stability across the front, as represented by $\psi$ in (8), was tested by setting $\psi=0.3$, close to its value over warm water. The resulting coupling is only $10 \%$ weaker than for the standard calculation, $\alpha_{C}=1.8 \times 10^{-2} \mathrm{~N} \mathrm{~m}^{-2}{ }^{\circ} \mathrm{C}^{-1}$. These results indicate that the primary term responsible for the change in surface stress across the front is the change in the vertical mixing coefficient that results 


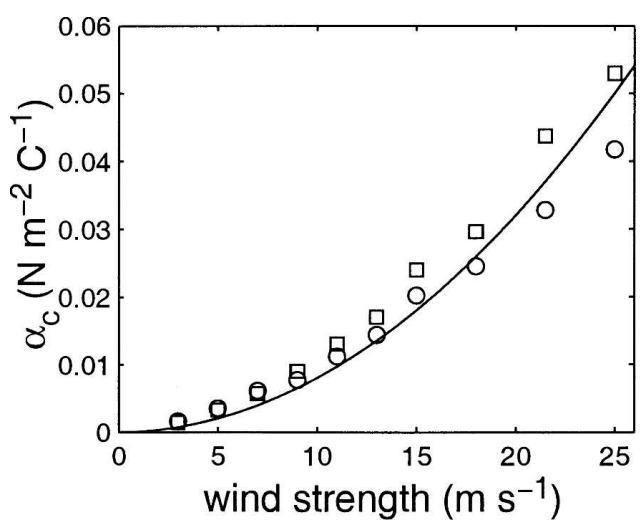

FIG. 6. The coupling coefficient $\alpha_{C}$ measuring the strength of the change in wind stress for each degree of change in SST across the front. Circles indicate calculations from cold to warm; squares indicate calculations from warm to cold. The solid line is the quadratic fit $\alpha_{C}=8 \times 10^{-5} U^{2}$.

directly from an increase in the flux Richardson number over warm water. The stability effect on the drag coefficient $C_{D}$ is of much less importance, consistent with the analysis of O'Neill et al. (2005) for the Agulhas region.

The strength of the coupling $\alpha_{C}$ is most sensitive to the strength of the geostrophic cross-front wind. A series of calculations has been carried out in which the initial wind was varied between 3 and $25 \mathrm{~m} \mathrm{~s}^{-1}$ for both warm-to-cold and cold-to-warm cases. The resulting coupling coefficient $\alpha_{C}$ is shown in Fig. 6 as a function of geostrophic wind strength. There is a nearly quadratic relationship for $\alpha_{C} \approx C U^{2}$ with $C=8 \times 10^{-5} \mathrm{~N}$ $\mathrm{s}^{2} \mathrm{~m}^{-4}{ }^{\circ} \mathrm{C}^{-1}$. The strength of coupling is slightly larger for the warm-to-cold calculations at higher wind speeds. This is due primarily to a lower stress over cold water, within the internal boundary layer, for the warmto-cold cases as compared to the stress over cold water for the cold-to-warm cases. The lower stress gives a larger change in stress across the front, and thus a larger coupling coefficient.

\section{b. Momentum budgets}

The change in surface winds occurs primarily in the transition region in the vicinity of the ocean front. The forces responsible for this acceleration or deceleration are revealed through analysis of the terms in the zonal momentum equation:

$$
\begin{aligned}
U_{t}= & -U U_{x}-V U_{y}-\dot{\sigma} U_{\sigma}+f V+\left(K_{M} U_{z}\right)_{z} \\
& +K_{H} \nabla^{4} U+C_{P} \theta_{V}\left(\pi_{x}^{\prime}+\sigma_{x} \pi_{\sigma}^{\prime}\right) .
\end{aligned}
$$

Lowercase subscripts indicate partial differentiation. The first three terms on the right-hand side represent zonal, meridional, and vertical advection of zonal momentum. The fourth term is the Coriolis term. Turbulent mixing is represented by the fifth term, where the vertical mixing coefficient $K_{M}$ is determined by the Mellor and Yamada (1982) parameterization (2); $K_{H}$ is a lateral mixing coefficient used to control numerical instabilities. The final term is the zonal pressure gradient. The Exner function $\pi=\left(p / p_{00}\right)^{R_{d} / C_{P}}=\bar{\pi}(z)+$ $\pi^{\prime}(x, y, z, t)$, where $p$ is pressure, $p_{00}$ is a reference pressure, $C_{P}$ is the specific heat of air at constant pressure, $R_{d}$ is the dry gas constant, and $\theta_{V}$ is the virtual potential temperature.

\section{1) WARM-TO-COLD CASE}

Vertical sections of the dominant terms on the righthand side of the zonal momentum equation are shown in Fig. 7. Because the flow is in steady state, the sum of all these terms is essentially zero. The sign convention is such that positive terms are acting to accelerate the flow to the east. The steady balance in the model is primarily between zonal advection of momentum, the Coriolis term, and turbulent mixing, with a small contribution from the pressure gradient, all other terms in (10) being negligible. The SST front is centered at 400$\mathrm{km}$ longitude with an $e$-folding scale of $30 \mathrm{~km}$. Upwind of the front, the primary balance throughout the boundary layer is between the Coriolis term and turbulent mixing. The TKE is acting to slow the westward flow, and the Coriolis term is providing westward momentum at the expense of the meridional momentum. The pressure gradient is weakly negative, of the same sign as the Coriolis term and slightly helping to offset the turbulent mixing. The pressure gradient term is small because the flow upwind of the front is nearly in equilibrium (1D balance) and there are no large-scale zonal pressure gradients imposed on the flow. Horizontal advection is weak, again indicating that this is essentially a one-dimensional equilibrium balance. Turbulent mixing increases rapidly as near-surface parcels are advected across the front. This is the shallow internal boundary layer discussed by Skyllingstad et al. (2006) and Mahrt et al. (2004). This change in mixing is offset by an increasingly negative horizontal advection term as the surface winds slow down with little change in the pressure gradient term. Downwind of the front the Coriolis term becomes increasingly negative within the internal boundary layer, growing to the point that it balances the turbulent mixing and the horizontal advection term goes to zero. At this point, the horizontal velocity is no longer decreasing and the flow returns to an essentially one-dimensional balance, the new Ekman-like balance for the shallow boundary layer over the cold SST. 

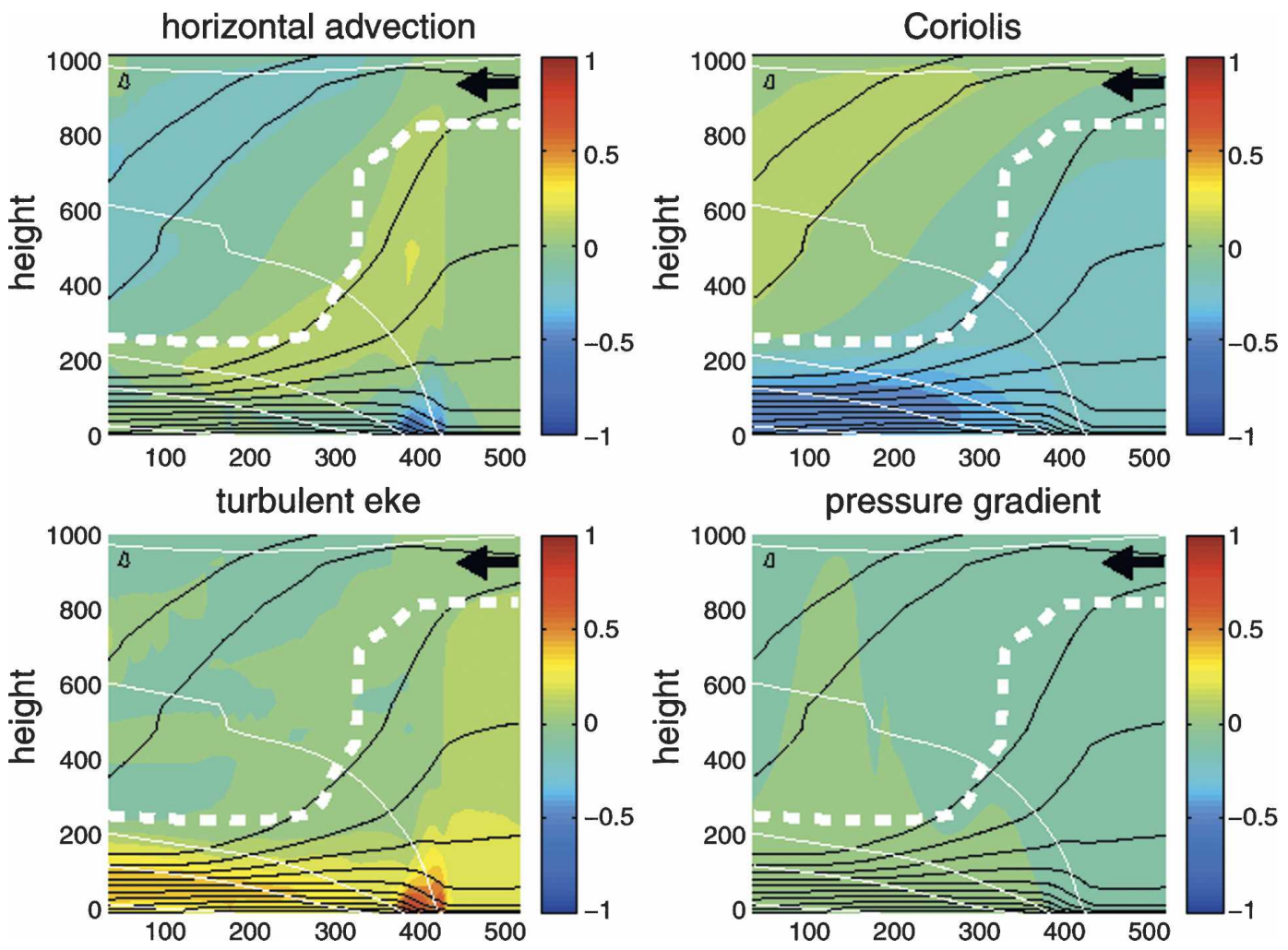

FIG. 7. Vertical slices of the dominant terms in the zonal momentum balance for the case of warm-to-cold flow (zonal flow direction is indicated by the bold black arrow, units $10^{-3} \mathrm{~m} \mathrm{~s}^{-2}$ ). The thin white contours are potential temperature (contour interval: $1^{\circ} \mathrm{C}$ ), and the thick white dashed line is the top of the planetary boundary layer.

In the upper boundary layer, the turbulent mixing rapidly drops to near zero as the front is crossed. This is accompanied by a positive horizontal advection term, coincident with the increase in winds to the west. These changes occur in the immediate vicinity of the front. Two hundred kilometers downwind of the front, the Coriolis term becomes positive above the shallow internal boundary layer. This is balanced by the horizonal advection term as the upper-level zonal winds slow down.

The dynamical balances can be subdivided into two regions: the lower boundary layer (height less than the internal boundary layer over cold water) and the upper boundary layer. The balances within these regimes are most clearly demonstrated with terms in the momentum equation taken at constant height. For the nearsurface winds (Fig. 8), the primary balance in the frontal region, in a Lagrangian framework, is between turbulent mixing and acceleration. Following an air parcel, the change in the vertical divergence of the horizontal stress due to turbulent mixing occurs very quickly as the parcel flows over colder water. This is initially balanced by the horizontal advection term such that the parcel loses zonal momentum. This rapid change in the stress divergence is due to a change in the vertical scale of the boundary layer, not due to an increase in the vertical mixing coefficient $K_{M}$. The mixing coefficient actually decreases rapidly across the front, primarily due to a decrease in the flux Richardson number. The effect of turbulent mixing on the momentum budget within the boundary layer nonetheless increases because the vertical scale of the boundary layer becomes very small as the cold SST stabilizes the lower atmosphere.

The Coriolis term is nearly constant over the horizontal length scale of the front. This is because the Coriolis term cannot change significantly for times scales less than $f^{-1}$ or, following the flow, for length scales less than $L_{i}=U f^{-1}$. For a $15 \mathrm{~m} \mathrm{~s}^{-1}$ wind speed, this gives a length scale of $L_{i}=150 \mathrm{~km}$, wider than the frontal width. It is over this length scale $\left(L_{i}\right)$ that the Coriolis term increases in magnitude such that it balances the new level of turbulent mixing within the shallow internal boundary layer and the flow arrives at the new one-dimensional balance.

In the upper boundary layer, the balance on the upwind side of the front is mainly between turbulence and Coriolis, with a small contribution from the zonal pressure gradient. As air flows over the front, the turbulent 

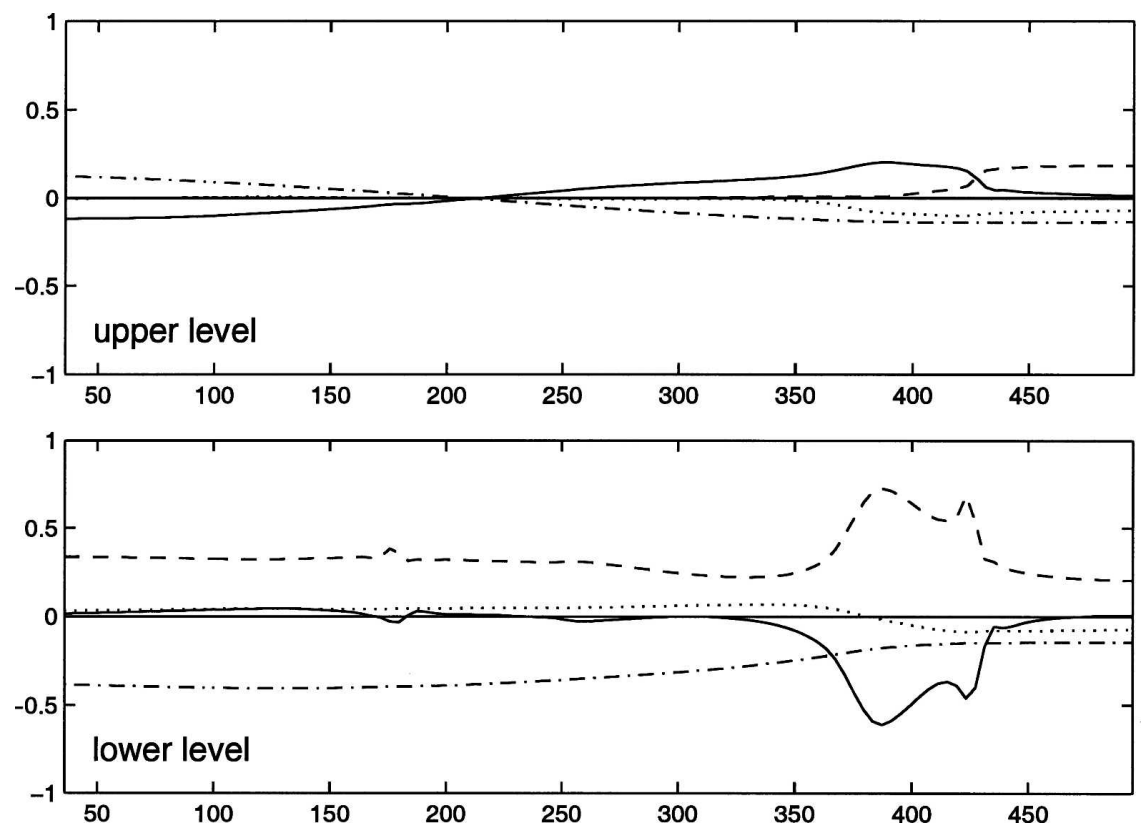

FIG. 8. Terms in the zonal momentum balance for the upper level (455-m height) and lower level (5-m height) of the planetary boundary layer $\left(10^{-3} \mathrm{~m} \mathrm{~s}^{-2}\right)$. Solid black: zonal advection; solid red: Coriolis; dashed black: turbulent mixing; dotted black: pressure gradient; and solid green: vertical advection. The ocean front is centered at $400 \mathrm{~km}$.

mixing rapidly drops to zero. However, as stated for the lower boundary layer, the Coriolis term cannot change that rapidly, so the Coriolis force goes into acceleration of the horizontal flow. The change in zonal velocity in turn forces an acceleration of the meridional wind through the Coriolis force in the meridional momentum equation. This transfer of momentum between zonal and meridional flows continues as an inertial oscillation following the air parcel downwind of the front. The turning of the velocity vector, and its balance with the Coriolis term, are evident in Fig. 8a. The wavelength of this inertial lee wave is approximately $2 \pi U / f \approx 1000 \mathrm{~km}$ for a $15 \mathrm{~m} \mathrm{~s}^{-1}$ wind, in general agreement with the model result. Calculations in a wider domain $(1600 \mathrm{~km})$ show that the oscillation continues farther to the west, consistent with this interpretation. This is anologous to the nocturnal jet in which turbulent mixing ceases at night and an inertial oscillation sets up in the upper boundary layer (Blackadar 1957).

\section{2) COLD-TO-WARM CASE}

Vertical sections of the dominant terms in the zonal momentum equation are shown in Fig. 9. The steady balance in the model is again primarily between zonal advection of momentum, the Coriolis term, and turbulent mixing with a small contribution from the pressure gradient. Upwind of the front, the same Ekman-like balance is found throughout the boundary layer. As the parcels cross the front from cold to warm SST, there is a rapid change in the turbulent mixing term: it decreases in magnitude near the surface and increases in magnitude in the upper boundary layer. This change is balanced by an acceleration of the winds in the lower boundary layer and a deceleration of the winds in the upper boundary layer. The potential temperature within the boundary layer increases downwind of the front and remains very weakly stratified. The pressure gradient increases downwind of the front to partially offset the turbulent mixing. Two hundred kilometers downwind of the front the balance is again Ekman-like with only weak changes in the wind strength.

The individual terms in the lower boundary layer show that the change in turbulent mixing is offset by a change in horizontal advection with very little change in the Coriolis term on the length scale of the front (Fig. 10). Over most of the region where the surface winds are increasing, the turbulent mixing term does not tend to increase the wind speed but, with the exception of a very small region on the leading edge of the front, acts to slow the winds down. The acceleration takes place because, with the decrease in momentum loss due to vertical mixing, the Coriolis term is largely unbalanced. Most of the gain in zonal momentum near the surface comes from the Coriolis torque, not downward mixing of momentum.

On a somewhat larger length scale, the pressure gra- 

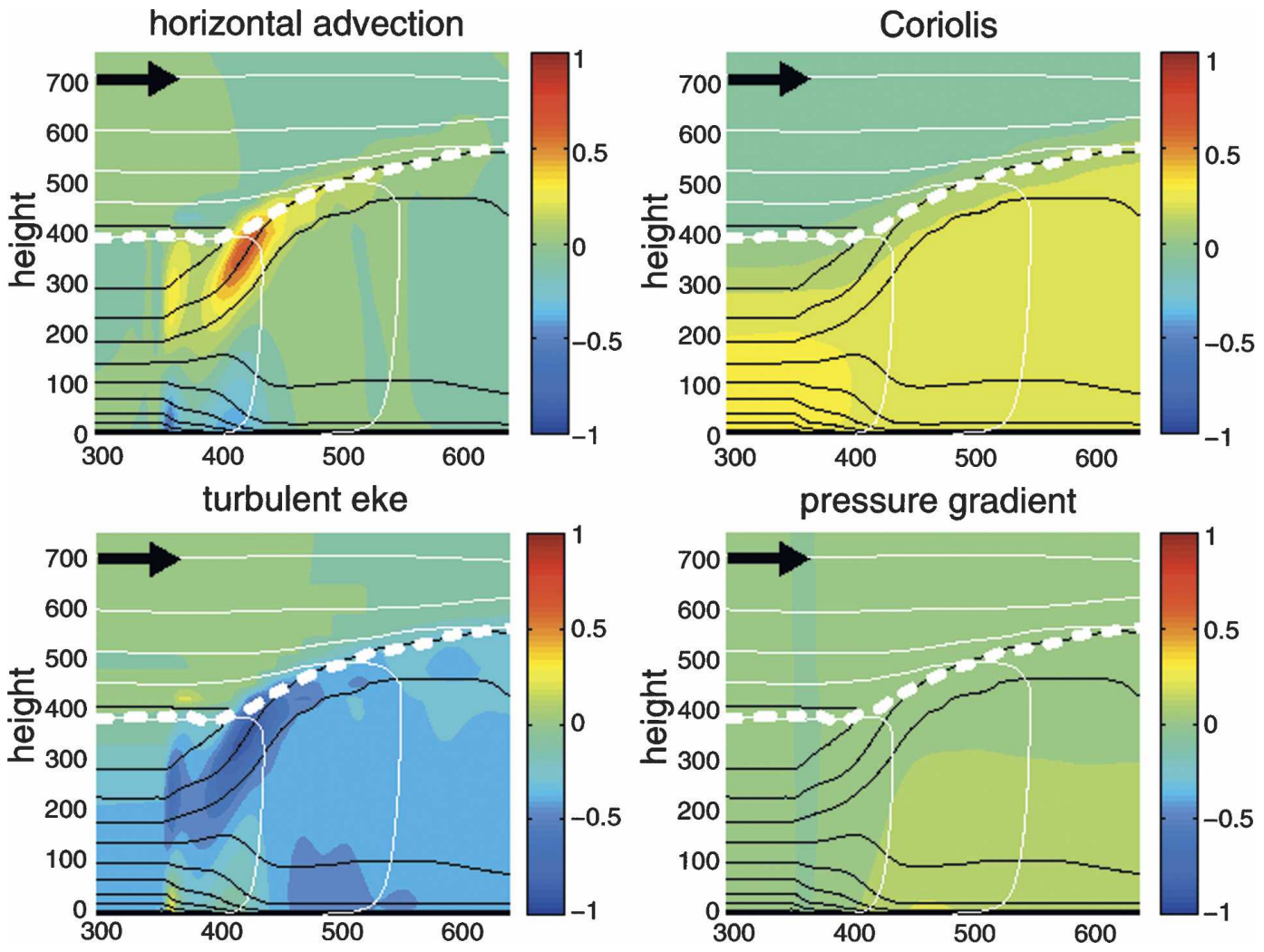

FIG. 9. Vertical slices of the dominant terms in the zonal momentum balance for the case of cold-to-warm flow (zonal flow direction is indicated by the bold black arrow, units $10^{-3} \mathrm{~m} \mathrm{~s}^{-2}$ ). The thin white contours are potential temperature (contour interval: $1^{\circ} \mathrm{C}$ ), and the thick white dashed line is the top of the planetary boundary layer.
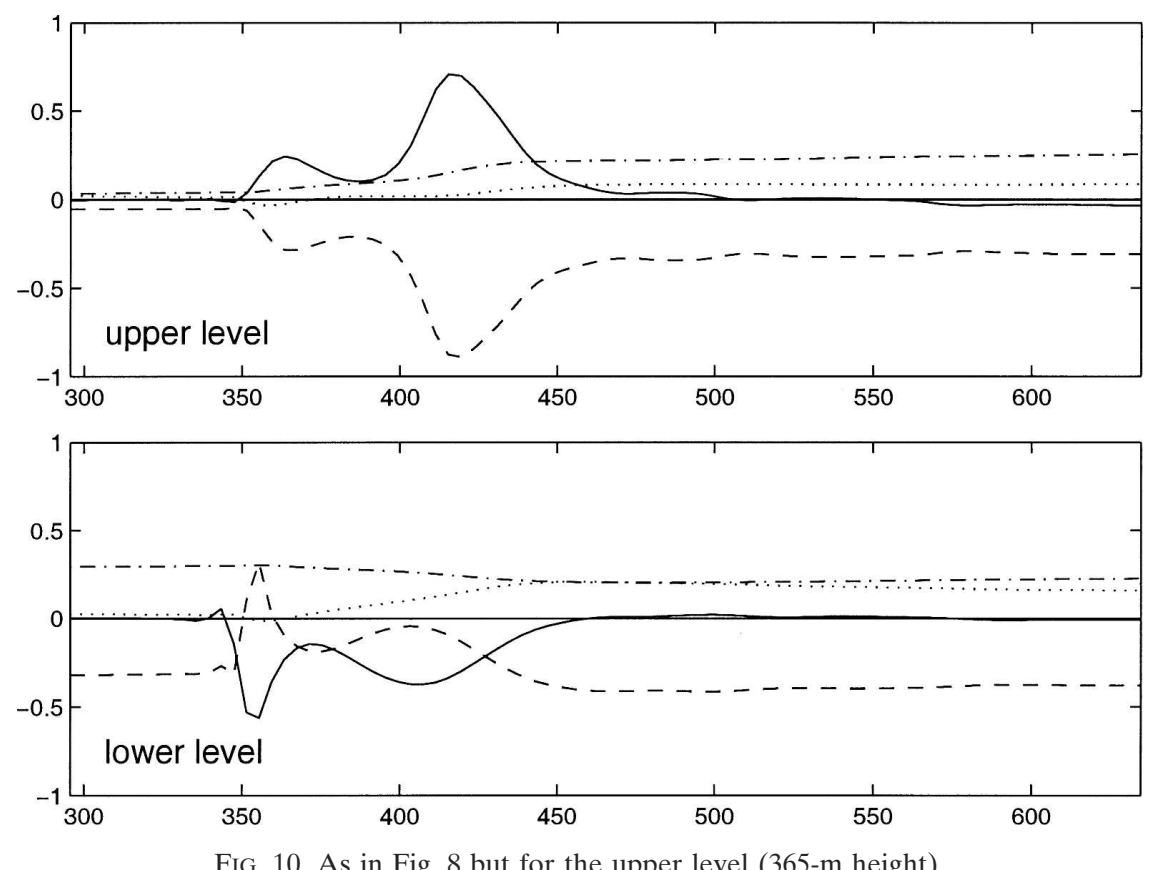

FIG. 10. As in Fig. 8 but for the upper level (365-m height). 

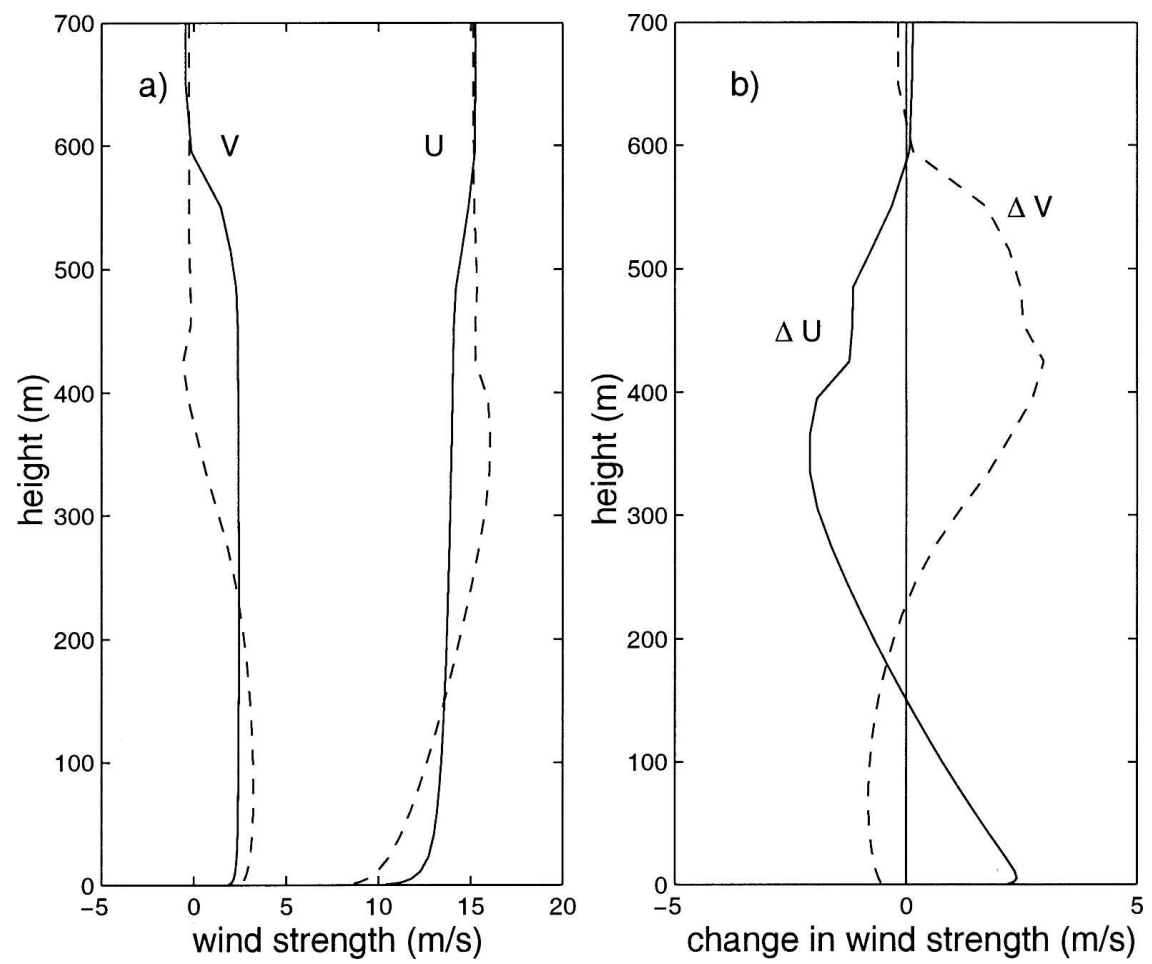

FIG. 11. Vertical profiles of (a) zonal and meridional velocities on the cold side ( $x=200 \mathrm{~km}$; dashed) and warm side ( $x=600 \mathrm{~km}$; solid) of the front; (b) change in zonal (solid) and meridional (dashed) velocities across the front.

dient increases and the Coriolis term decreases. The pressure gradient becomes important for the acceleration of the flow but only over the downwind edge of the front, by which time most of the acceleration has already taken place. The length scale over which the pressure gradient changes is controlled by a balance of lateral advection of the upwind stratification and vertical mixing, which can be written as $L_{P}=U H^{2} / K_{T}$, where $H$ is the boundary layer thickness and $K_{T}$ is the vertical diffusion coefficient due to turbulent mixing. For a linear Ekman layer, the boundary layer thickness $H \propto\left(\mathrm{K}_{\mathrm{M}} / f\right)^{1 / 2}$ (Pedlosky 1987) and $L_{P}=L_{i} P_{r}$, where $P_{r}=K_{M} / K_{T}$ is the turbulent Prandtl number. For a Prandtl number of $O(1)$, as is found in the model, the pressure gradient would change over a length scale similar to the Coriolis term. Several hundred kilometers downwind of the front, the boundary layer thickness and surface winds are changing only slowly, and the new Ekman-like balance is achieved.

Upwind of the front, at $365-\mathrm{m}$ height, the flow is nearly in geostrophic balance and the Coriolis and turbulent mixing terms are small because it is near the top of the planetary boundary layer. As the front is encountered, the boundary layer deepens and a drag on the flow is induced by turbulent mixing. As the zonal flow decreases, the meridional flow increases on a length scale of $L_{i}$ (increasing the Coriolis term) in order to balance the turbulent mixing. As the Coriolis term spins up, the zonal deceleration term decreases until the new Ekman balance is attained.

Given the similar pattern in momentum loss in the upper boundary layer and momentum gain in the lower boundary layer due to vertical mixing, it is tempting to interpret this as simply a redistribution of momentum in the vertical bringing high momentum down toward the surface. However, integration of this vertical mixing term indicates that the momentum loss in the upper boundary layer greatly exceeds the momentum gain in the lower boundary layer due to turbulent mixing. The velocity profiles upwind and downwind of the front are shown in Fig. 11a. In the lower boundary layer, the zonal velocity increases and the meridional velocity decreases from the cold side to the warm side of the front. The opposite trend is found in the upper boundary layer. This is reflected in the change in zonal $(\Delta U)$ and meridional $(\Delta V)$ velocities across the front shown in Fig. 11b. To a large degree, the loss of zonal momentum in the upper boundary layer is accompanied by a gain in momentum of the meridional flow over a similar height range. The loss of zonal momentum in the upper 
boundary layer, as measured by $\int \Delta U d z$ where $\Delta U<0$, is $-513 \mathrm{~m}^{2} \mathrm{~s}^{-1}$, while the gain in meridional momentum is $635 \mathrm{~m}^{2} \mathrm{~s}^{-1}$, slightly exceeding that lost from the zonal momentum. Although there is also a gain in zonal momentum near the surface, its magnitude (integral over height range where $\Delta U>0$ ) is only $182 \mathrm{~m}^{2} \mathrm{~s}^{-1}$, much less than the momentum loss in the upper boundary layer. However, the loss in meridional momentum near the surface is $-139 \mathrm{~m}^{2} \mathrm{~s}^{-1}$, or about $75 \%$ of the momentum gained by the zonal flow.

These results support the interpretation that the changes in zonal flow arise largely as a result of exchanging momentum with the meridional flow through the Coriolis terms, not by a vertical redistribution of momentum due to changes in the turbulent mixing. There is a clear parallel between this adjustment of the horizontal momentum balances and that of the inertial lee wave that arises with the abrupt loss of turbulent mixing across the front in Fig. 8. It should be noted, however, that the Coriolis terms can only exchange momentum between the zonal and meridional components of the flow, not change the total momentum at any given level, so that the turbulent mixing and pressure gradient terms are important for the net change in momentum at each level.

\section{Other flow regimes}

The primary regime of interest is midlatitude, strong winds blowing across narrow sea surface temperature fronts. The importance of the Coriolis term in the momentum balances is different from what has been previously found, and the scaling suggests that this may be dependent on the strength of the winds. A few sensitivity calculations have been carried out to see how the terms responsible for the acceleration or deceleration of the near-surface winds change for weaker winds and at low latitudes.

\section{a. Weak winds}

The spatial scale over which the pressure gradient can change is dependent on the strength of the zonal wind because it arises as a result of competition between horizontal advection of the upwind stratification and erosion due to vertical mixing. The warm-to-cold and cold-to-warm cases have been recalculated with initial winds of $\pm 3 \mathrm{~m} \mathrm{~s}^{-1}$. For this value of winds, the inertial length scale $L_{i}=L_{f}$ and, for a Prandtl number of $1, L_{P}=L_{f}$, so it is expected that the pressure gradient may become more important than was found for the strong wind cases. The case of cold to warm is shown in Fig. 12. The boundary layer thickness upwind of the front is shallower, reflecting less turbulence generated by the weaker atmospheric winds. The boundary layer also approaches its equilibrium depth in less distance downwind from the front because the advection of the upwind stratification over the front is weaker. The temperature in the atmospheric boundary layer approaches the sea surface temperature within $200 \mathrm{~km}$ of the front, less distance than for the strong wind case. This results in a stronger zonal gradient in the temperature within the atmospheric boundary layer and, thus, a stronger zonal pressure gradient. The balance upwind of the front is between turbulent mixing and the Coriolis parameter, similar to the previous high wind case (Fig. 13). However, in the frontal region the turbulent mixing becomes increasingly negative and works to decelerate the zonal flow. This is opposite to what was found for strong winds. The acceleration of the flow and this turbulent mixing are balanced by the zonal pressure gradient term. This balance is fundamentally different than was found for the strong wind case.

For the case of warm-to-cold flow, the deceleration in the frontal region is driven both by the lateral pressure gradient and the increase in turbulent mixing (Fig. 14). As for the cold-to-warm case, the pressure gradient changes on the lateral scale of the front, enabling it to increase sufficiently to influence the momentum balance in the frontal region. The Coriolis term changes rapidly in response, also on the spatial scale of the front. Downwind of the front the pressure gradient and turbulent mixing together balance the Coriolis term.

In each of these weak wind cases the pressure gradient has the dominant role in accelerating or decelerating the zonal winds near the surface. This is a direct result of the weaker winds allowing the turbulent mixing of temperature in the boundary layer to act over the same horizontal scales as the front itself. It is the crossfront winds that are important in setting this length scale, so the pressure gradient term may also become important for strong winds with only a weak cross-front component.

\section{b. Low latitudes}

The importance of the Coriolis term in the acceleration of both the upper and lower level winds arises because the basic balance in the turbulent boundary layer away from the frontal region is between the Coriolis term and turbulent mixing. For the case of tropical instability waves, which are centered near $2^{\circ} \mathrm{N}$, the Coriolis parameter is much weaker and less likely to play such a pivotal role in the momentum balance.

The cold-to-warm calculation applied at $2^{\circ} \mathrm{N}$ shows a much different balance than was found at midlatitudes. The flow accelerates over the warm water, as found for 

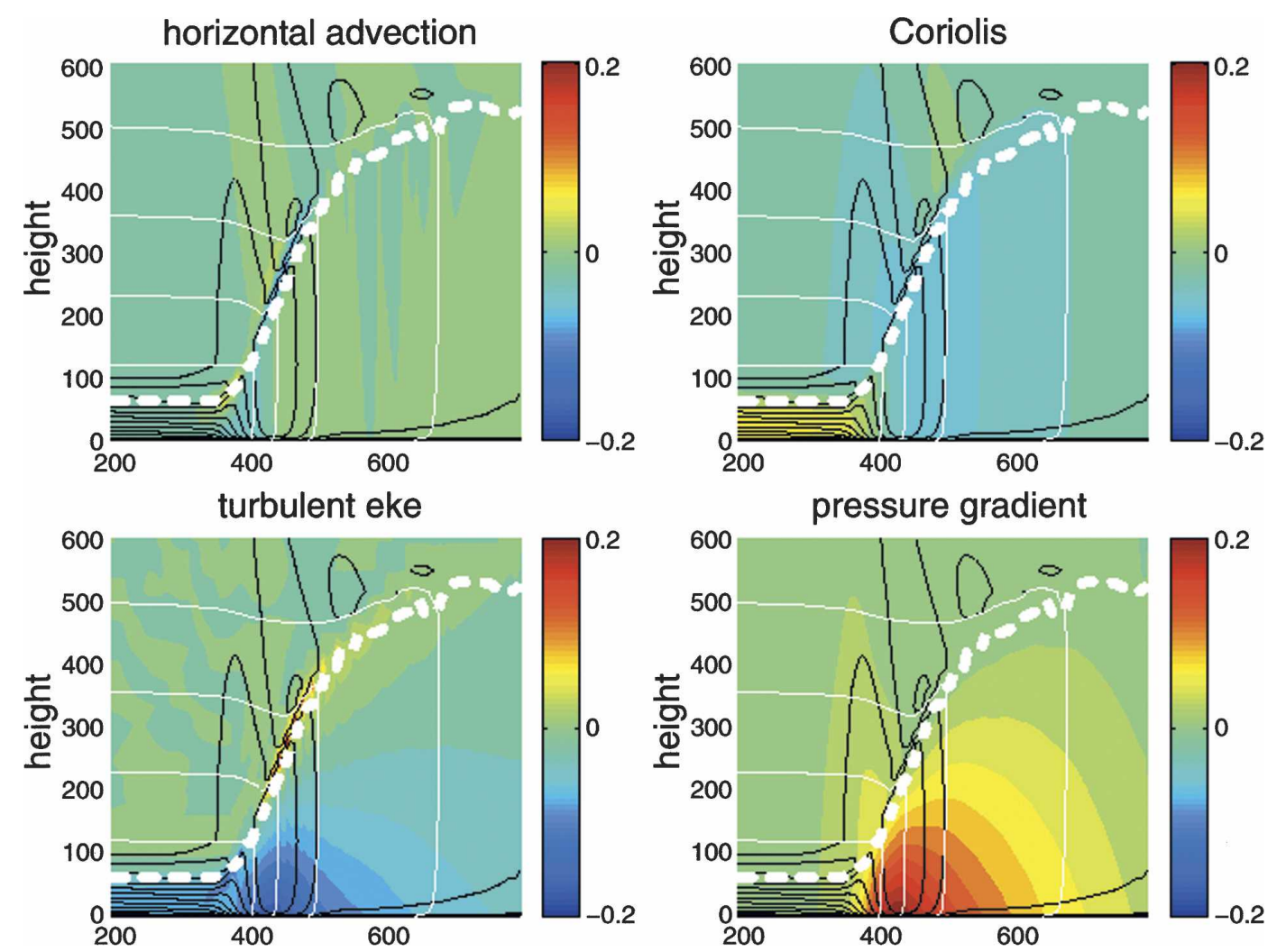

FIG. 12. Vertical slices of the dominant terms in the zonal momentum balance for the case of cold-to-warm flow $\left(10^{-3} \mathrm{~m} \mathrm{~s}^{-2}\right)$ with an initial wind of $3 \mathrm{~m} \mathrm{~s}^{-1}$. The thin white contours are potential temperature (contour interval: $1^{\circ} \mathrm{C}$ ); the thick white dashed line is the top of the planetary boundary layer.

the other cases, but now it is balanced by both turbulent mixing and the pressure gradient term (Fig. 15). Consistent with the results of Wallace et al. (1989), Hashizume et al. (2002), and de Szoeke and Bretherton (2004), the turbulent mixing now acts to accelerate the flow at 5-m height. This is different from the deceleration of the zonal flow due to vertical mixing found for the midlatitude cases, and dominates the momentum budget on the upwind side of the front. However, the pressure gradient rapidly grows so that it becomes more important than the turbulent mixing on the downwind side of the front, as found in the model study of Small et al. (2005). Far downwind of the front the turbulent mixing changes sign, retarding the zonal flow, and is balanced by the zonal pressure gradient.

As was the case for wind from warm-to-cold SSTs at midlatitudes, changes in the flux divergence of the turbulent mixing term dominate the slowing of the near-

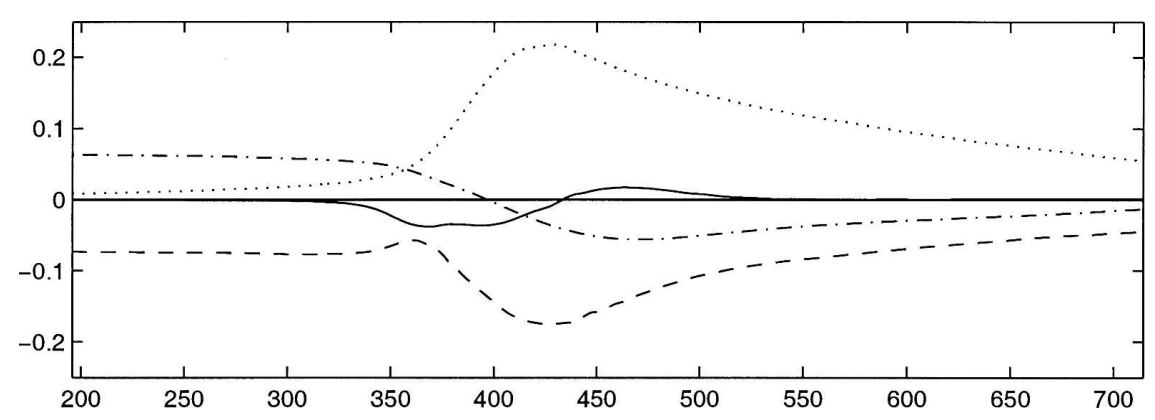

FIG. 13. Terms in the zonal momentum balance at 5 -m height $\left(10^{-3} \mathrm{~m} \mathrm{~s}^{-2}\right)$ for a case with $3 \mathrm{~m} \mathrm{~s}^{-1}$ initial winds (left to right). Solid black: zonal advection; solid red: Coriolis; dashed black: turbulent mixing; dotted black: pressure gradient; and solid green: vertical advection. 


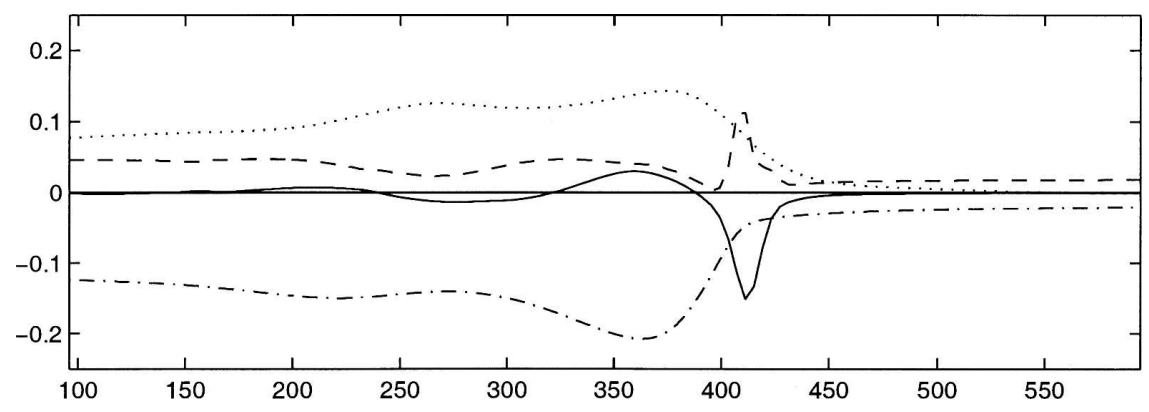

FIG. 14. As in Fig. 13 but for a case with $-3 \mathrm{~m} \mathrm{~s}^{-1}$ initial winds (right to left).

surface flow at low latitudes. However, the balance within the boundary layer far from the front is between turbulent mixing and the pressure gradient instead of between turbulent mixing and the Coriolis term. The warm-to-cold flow near the equator also does not result in the inertial oscillation in the upper boundary layer downwind of the front, which was found at midlatitudes.

\section{Discussion and summary}

The adjustment of the atmospheric boundary layer to changes in sea surface temperature at an ocean front has been explored for situations of atmospheric flow from warm to cold water and from cold to warm water. The model configuration and forcing are very idealized and are intended to represent generic, but typical, midlatitude conditions in the open ocean. The changes in the boundary layer structure found in the model (thickness, wind strength and direction) are qualitatively similar to what has been seen in observations and in other models. Most important is the positive correlation between surface wind stress and sea surface temperature and boundary layer thickness. The magnitude of the change in surface stress resulting from the change in SST across the front is similar to what has been inferred from satellite observations. It is shown that this is due primarily to changes in the vertical mixing of momentum across the front, which results from changes in the flux Richardson number over warm and cold water. The explicit dependence of surface drag on the stability of the boundary layer was found to play a much weaker role in the coupling, only $O(10 \%)$. The magnitude of the cross-front geostrophic wind was found to be most important for the coupling strength with a quadratic dependence on wind speed.

For the midlatitude, strong wind cases studied here, the dynamics in the boundary layer upwind and downwind of the front, for both warm-to-cold and cold-towarm flows, is described as Ekman-like because the momentum balance is primarily between turbulent mixing and the Coriolis force. The details of the boundary layer structure and its parameter dependence are likely more complicated than for the linear Ekman layer with constant mixing because of the presence of stratification and a nonconstant vertical mixing coefficient. Nonetheless, the similarity suggests an analogous momentum balance in which the vertical mixing acts to slow the flow throughout the boundary layer, and the energy lost by the wind at the surface of the ocean through stress is provided by the along-front flow down the background pressure gradient. The acceleration of surface winds over warm water is not provided by mixing momentum down from above, but is instead provided by a deceleration of the along-front winds. Similarly, the deceleration of the upper-level winds is

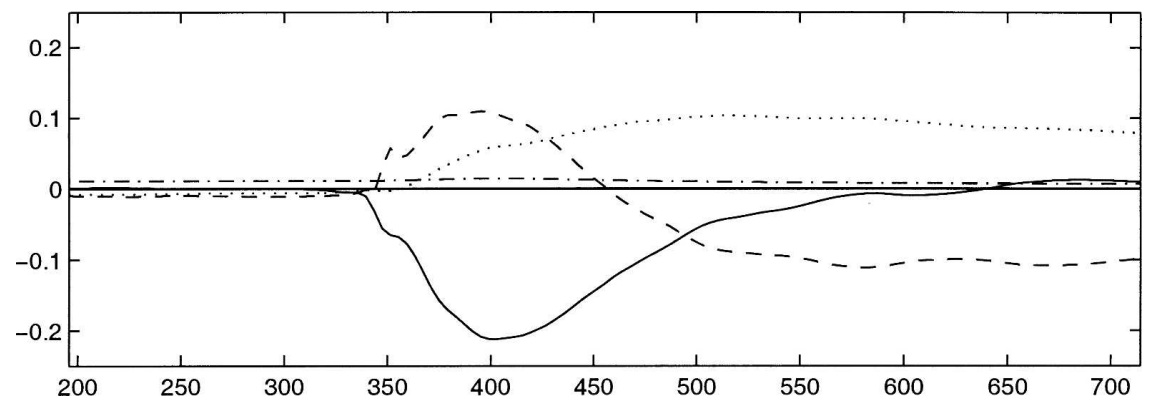

FIG. 15. As in Fig. 13 but for a case with $15 \mathrm{~m} \mathrm{~s}^{-1}$ initial winds at $2^{\circ} \mathrm{N}$. 
largely balanced by an increase in the momentum of the along-front winds at similar heights.

The acceleration/deceleration of the surface winds across the front can be interpreted as a result of the disparity in length (or time) scales over which the terms in the momentum equation can change. The turbulent mixing changes very rapidly in the present model because it is essentially a one-dimensional balance in the vertical; lateral advection of turbulent energy is small. The other terms in the momentum equation are more strongly influenced by rotation and lateral advection and hence are subject to different constraints on how rapidly they can change as parcels are advected across the front. There are three important length scales that define different dynamical regimes: one associated with the width of the front, $L_{f}$; one associated with the length scale over which the Coriolis term can change, $L_{i}=U / f$; and finally the length scale over which the pressure gradient adjusts, $L_{P}=U H^{2} / K_{T}$. For typical midlatitude, strong wind frontal regimes, $L f<L_{i}, L_{P}$. The momentum changes over a smaller horizontal length scale in response to rapid changes in the strength of vertical mixing than does temperature (or pressure) because the vertical mixing of momentum acts over a smaller vertical length scale than does the vertical mixing of temperature. This is because temperature is well mixed over the planetary boundary layer depth while momentum has significant vertical shear over the boundary layer because of the Ekman-like momentum balance and the importance of the Coriolis terms.

The pressure gradient plays a secondary role in the strong wind, midlatitude cases studied here, although previous modeling studies have identified the pressure gradient as being responsible for the acceleration over warm water. Calculations with weaker winds, so that $L_{P}$ $=O\left(L_{f}\right)$, result in the pressure gradient being the primary term responsible for the change in wind speed over the front. The weaker winds allow the vertical mixing of temperature to act on spatial scales of the front, and thus allow sufficient pressure gradient to develop in the vicinity of the front to alter the momentum balances. The balances were also different for the case of cold-to-warm flow near the equator. The turbulent mixing accelerates the near-surface flow directly over the front, consistent with the previous idea that the change in surface winds over the tropical instability waves results from a downward mixing of momentum from above, although it reverses sign downwind of the front to slow the winds. The pressure gradient was also partly responsible for accelerating the near-surface winds on the downwind side of the front, and balances the turbulent mixing far downwind of the front.

These results suggest that the terms responsible for the change in surface winds in the vicinity of oceanic fronts vary depending on the environment. An attempt has been made here to explore one region of parameter space, strong midlatitude winds over narrow oceanic fronts. The general importance of each of the terms in the momentum equation for different parameters, most notably at low latitudes and for weaker cross-front winds, has yet to be quantified. The results from this and previous studies suggest that each of these terms can be of importance in certain conditions. This makes the finding from satellite data that the magnitude of the change in wind stress is nearly linearly related to the change in sea surface temperature across the front, for a wide range of latitudes and frontal strength, somewhat surprising. This supports the interpretation of Samelson et al. (2006) that the equilibrium balance far from the front is not dependent on the details of the transition region in the vicinity of the front and that the function of the momentum budgets in the transition region is primarily to adjust to a new one-dimensional balance far from the front. However, O'Neill et al. (2005) find a clear seasonal signal in the coupling strength $\alpha_{C}$ over the Agulhas front, which indicates that the background environment (such as stratification and wind strength) does influence the strength of the coupling.

Acknowledgments. This work was supported by the Office of Naval Research Grant N00014-05-1-0300. Coupled COAMPS/ROMS code was generously provided by Natalie Perlin, Roger Samelson, and Eric Skyllingstad from Oregon State University. Natalie Perlin is thanked for answering numerous questions on the coupled model and for helping me get it running on computers at the Woods Hole Oceanographic Institution. Jeff Dusenberry also provided invaluable assistance with getting the code running on the linux cluster at WHOI. Comments and suggestions from three anonymous reviewers helped to clarify the discussion.

\section{REFERENCES}

Blackadar, A. K., 1957: Boundary layer wind maxima and their significance for the growth of the nocturnal inversion. Bull. Amer. Meteor. Soc., 38, 283-290.

_ 1962: The vertical distribution of wind and turbulent exchange in a neutral atmosphere. J. Geophys. Res., 67, 10061015.

Chelton, D. B., and Coauthors, 2001: Observations of coupling between surface wind stress and sea surface temperature in the eastern tropical Pacific. J. Climate, 14, 1479-1498.

_-, M. G. Schlax, M. H. Freilich, and R. F. Milliff, 2004: Satellite measurements reveal persistent small-scale features in ocean winds. Science, 303, 978-983.

de Szoeke, S. P., and C. S. Bretherton, 2004: Quasi-Lagrangian 
large eddy simulations of cross-equatorial flow in the East Pacific atmospheric boundary layer. J. Atmos. Sci., 61, 18371858.

Hashizume, H., S.-P. Xie, M. Fujiwara, M. Shiotani, T. Watanabe, Y. Tanimoto, W. T. Liu, and K. Takeuchi, 2002: Direct observations of atmospheric boundary layer response to SST variations associated with tropical instability waves over the eastern equatorial Pacific. J. Climate, 15, 3379-3393.

Hayes, S. P., M. J. McPhaden, and J. M. Wallace, 1989: The influence of sea-surface temperature on surface wind in the eastern equatorial Pacific: Weekly to monthly variability. J. Climate, 2, 1500-1506.

Hodur, R. M., 1997: The Naval Research Laboratory's Coupled Ocean/Atmosphere Mesoscale Prediction System (COAMPS). Mon. Wea. Rev., 125, 1414-1430.

Jury, M. R., and N. Walker, 1988: Marine boundary layer modification across the edge of the Agulhas Current. J. Geophys. Res., 93, 647-654.

Lindzen, R. S., and S. Nigam, 1987: On the role of sea surface temperature gradients in forcing low-level winds and convergence in the Tropics. J. Atmos. Sci., 44, 2418-2436.

Louis, J.-F., 1979: A parametric model of vertical eddy fluxes in the atmosphere. Bound.-Layer Meteor., 17, 187-202.

Mahrt, L., D. Vickets, and E. Moore, 2004: Flow adjustments across sea-surface temperature changes. Bound.-Layer Meteor., 111, 553-564.

Mellor, G. L., and T. Yamada, 1982: Development of a turbulence closure model for geophysical fluid problems. Rev. Geophys. Space Phys., 20, 851-875.

Nonaka, M., and S.-P. Xie, 2003: Covariations of sea surface temperature and wind over the Kuroshio and its extension: Evidence for ocean-to-atmosphere feedback. J. Climate, 16, 1404-1413.

O'Neill, L. W., D. B. Chelton, and S. K. Esbensen, 2003: Observations of SST-induced perturbations of the wind stress field over the Southern Ocean on seasonal timescales. J. Climate, 16, 2340-2354.

,,,--- , and F. J. Wentz, 2005: High-resolution satellite measurements of the atmospheric boundary layer response to SST variations along the Agulhas Return Current. J. Climate, 18, 2706-2723.

Pedlosky, J., 1987: Geophysical Fluid Dynamics. Spinger-Verlag, $710 \mathrm{pp}$.

Perlin, N., E. D. Skyllingstad, R. M. Samelson, and P. L. Barbour, 2007: Numerical simulation of air-sea coupling during coastal upwelling. J. Phys. Oceanogr., in press.

Samelson, R. M., E. D. Skyllingstad, D. B. Chelton, S. K. Esbensen, L. W. O'Neill, and N. Thum, 2006: On the coupling of wind stress and sea surface temperature. J. Climate, 19, $1557-1566$.

Shchepetkin, A. F., and J. C. McWilliams, 2005: The Regional Ocean Modeling System (ROMS): A split-explicit, free surface, topography-following coordinate ocean model. Ocean Modell., 9, 347-404.

Skyllingstad, E. D., R. Samelson, L. Mahrt, and P. Barbour, 2005: A numerical modeling study of warm offshore flow over cool water. Mon. Wea. Rev., 133, 345-361.

- D. Vickers, L. Mahrt, and R. Samelson, 2006: Effects of mesoscale sea-surface temperature fronts on the marine atmospheric boundary layer. Bound.-Layer Meteor., 123, 219 237.

Small, R. J., S.-P. Xie, and Y. Wang, 2003: Numerical simulation of atmospheric response to Pacific tropical instability waves. J. Climate, 16, 3723-3741.

,,--- S. K. Esbensen, and D. Vickers, 2005: Numerical simulation of boundary layer structure and cross-equatorial flow in the eastern Pacific. J. Atmos. Sci., 62, 1812-1830.

Smedman, A.-S., H. Bergström, and B. Grisogono, 1997: Evolution of stable internal boundary layers over a cold sea. $J$. Geophys. Res., 102, 1091-1100.

Song, Q., P. Cornillon, and T. Hara, 2006: Surface wind response to oceanic fronts. J. Geophys. Res., 111, C12006, doi:10.1029/ 2006JC003680.

Stull, R. B., 1988: An Introduction to Boundary Layer Meteorology. Kluwer Academic, $666 \mathrm{pp}$.

Sweet, W., R. Fett, J. Kerling, and P. LaViolette, 1981: Air-sea interaction effects in the lower troposphere across the north wall of the Gulf Stream. Mon. Wea. Rev., 109, 1042-1052.

Turner, J. S., 1973: Buoyancy Effects in Fluids. Cambridge University Press, $367 \mathrm{pp}$.

Vecchi, G. A., S.-P. Xie, and A. S. Fischer, 2004: Oceanatmosphere covariability in the western Arabian Sea. J. Climate, 17, 1213-1224.

Vickers, D., and L. Mahrt, 2006: Evaluation of the air-sea bulk formula and sea-surface temperature variability from observations. J. Geophys. Res., 111, C05002, doi:10.1029/ 2005JC003323.

Wallace, J. M., T. P. Mitchell, and C. Deser, 1989: The influence of sea-surface temperature on surface wind in the eastern equatorial Pacific: Seasonal and interannual variability. $J$. Climate, 2, 1492-1499.

Xie, S.-P., 2004: Satellite observations of cool ocean-atmosphere interaction. Bull. Amer. Meteor. Soc., 85, 195-208.

— W. W. Liu, Q. Liu, and M. Nonaka, 2001: Far-reaching effects of the Hawaiian Islands on the Pacific ocean-atmosphere system. Science, 292, 2057-2060. 